\title{
Distance Formation of Adolescents' Human Capital in the Paradigm of Sustainable Development
}

\author{
Natalia Tonkikh ${ }^{3,}$, Tatiana Markova ${ }^{3}$, Elitsa Dimitrova ${ }^{1}$, Tatyana Kotzeva ${ }^{2}$ \\ ${ }^{1}$ Institute for Population and Human Studies - Bulgarian Academy of Sciences \& Plovdiv University Paisii \\ Hilendarski \\ ${ }^{2}$ Burgas Free University \& Institute for Population and Human Studies - Bulgarian Academy of Sciences \\ ${ }^{3}$ Ural State University of Economics, Yekaterinburg, Russia \\ ${ }^{*}$ Corresponding author.Email: nvvorob1@mail.ru
}

\begin{abstract}
Coronavirus pandemic posed a great challenge to sustainable development of educational institutions around the world. The research aims to evaluate the methodological approach to assessing positive and negative characteristics of distance education and determine its prospects in terms of its influence on adolescents' sustainable human capital development. The qualitative characteristics of distance learning are assessed based on a narrative analysis of discursive essays written by thirteen-year-old adolescents at the end of the last academic quarter of 2020. The authors calculated the index of distance education sustainability by the parameter "quality" and compiled the rating of individual and collective trajectories in terms of frequency of mention. Overall, the methodological approach proves to be viable. Yet, the narrative analysis showed more negative rather that positive aspects of the distance education. Thus, the complete transition to distance education seems to be premature.
\end{abstract}

Keywords: Education for Sustainable Development (ESD), human capital, adolescents, distance education quality.

\section{INTRODUCTION}

The period of coronavirus pandemic posed a great challenge to educational institutions around the world. Within a very short period millions of educators and learners worldwide had to shift to online educational practices. It was an extremely traumatic and stressful period both for higher school [1] and secondary school stakeholders [2]. Face-to-face instruction was suspended and replaced with online educational practices and teaching materials resulting in a host of issues related to teaching and learning at a distance. Overall, national educational systems were subject to an unprecedented shock, that enabled the educational community to reveal how sustainable educational systems are in different countries.

The term sustainability was coined in 1980 when it was defined in terms of intergenerational equity [3]. Initially, this term referred to the discussions about the environment and ecosystems, but now sustainable development encompasses a broad range of economic, ecological, political, technological, and social issues. Šlaus \& Jacobs [4] argue that education being a primary lever, the development of human capital is the critical determinant of long-term sustainability. In terms of human capital, sustainability is defined as "the constancy or improvement in outcome indicators", one of these being the general and specific knowledge and skill sets of the population.

From this perspective, adolescence is considered to be a very special stage in the human capital development in terms of social interaction needs and learning requirements [5] that must be taken into account by educators to ensure satisfying learning experiences and high learning outcomes. For instance, it was found out that during the COVID-19 pandemic adolescents, deprived of the possibility to maintain human face-to-face interaction, tended to lose social contact that is vital for effective learning and development at this age [2]. The pandemic also affected the changes in adolescents' interpersonal relationship [6] and resulted in numerous negative psychological effects brought about dramatic changes in daily routines and lack of self-study and time management skills. 
Overall, it is internationally recognized that education is a significant contributor to global sustainable development agenda. In 2015, the UN launched the Sustainable Development Goals (SDGs) designed to create a better, healthier, and safer global community [7] Education being the fourth out of the seventeen SDGs aims to create effective learning environments, develop relevant employment skills and transmit knowledge for sustainable lifestyles. The concept of ESD, specified by UNESCO [8], consists in achieving a better understanding how the development of knowledge, skills, values, and attitudes can contribute to people's ability to create a sustainable future [9]. ESD is perceived as a learning strategy that will enable adolescents and adults to deal with global uncertainty and successfully adopt state-of-the-art practices for the future development of human community [10].

ESD is tightly linked to the concept of quality education [11]. On the one hand, sustainability-related teaching and learning practices enrich the curriculum and make it more future-oriented in terms of skills, values, and attitudes [12]. On the other hand, low quality education is certain to negatively affect the sustainable agenda in general. Although in educational context the term "quality" has multiple meanings, it can be measured quantitavely and qualitatively [13]. In the literature, there have been reported numerous attempts to evaluate the quality of distance learning [14] as well as its key issues, including effective teaching practices and communication patterns [15]. Yet, researchers are not unanimous in their assessments of the prospects of the shift to distance education practices.

This pilot study aims to test a methodological approach to determining distance education prospects with a view to ensure adolescents' sustainable human capital development. The study is based on adolescents' assessment of distance learning pros and cons. According to the authors' hypothesis, Russian schools and gymnasiums are not sufficiently provided with digital teaching materials for adolescents to obtain sustainable education in terms of "quality". In general, given distance learning has its advantages and disadvantages, adolescents are more likely to prefer the traditional "live" face-to-face form of education.

\section{MATERIALS AND METHODS}

It is proposed to assess the qualitative characteristics of distance learning based on a narrative analysis of textual material. This method of qualitative research has been used since the beginning of the 20th century, it allows to identify views, judgments, and emotional background in relation to the experience gained. It is proposed to use the results of teenagers' end-of-theacademic-year essay as a text material. The approbation was carried out in the seventh grade of the Russian gymnasium. According to the calendar-thematic plan of the "Russian language" discipline, seventh grade students were requested to write a discursive essay on the topic: "Distance learning: is it good or bad?" The formulation of the essay topic allows to isolate individual and collective judgments and opinions about learning at a distance in the students' works. The essay processing includes two components. The first component: reading the essay; identifying different types of errors - spelling, punctuation, grammatical; assessing the essay according to the criteria set. The second component: analyzing narratives and clustering them into two groups - positive and negative judgments; structuring individual and collective trajectories by type in each group.

Further, it is proposed to calculate the index of distance education sustainability by the parameter "quality" according to the formula

$$
I=\sqrt[2]{I_{1} \times I_{2}}
$$

where $I$ is the distance education sustainability index; $I_{1}$ is the ratio of distance learning positive qualities to its negative characteristics (it is calculated by dividing the number of positive collective trajectories by the number of negative trajectories identified as a result of the narrative analysis); $I_{2}$ is the intensity ratio index of the distance learning positive qualities to the negative ones. It is calculated as the ratio of the average frequency of mentioning positive trajectories to the average frequency of mentioning negative ones. The frequency of references is the proportion of works in which the selected type of trajectory is encountered in collective judgments.

An index exceeding 0.95 will be considered stable.

The subject of the research was the judgments of seventh-grade students of a typical Russian gymnasium located in a large city - the administrative centre of the region (Yekaterinburg, Sverdlovsk region). More than one and a half thousand schoolchildren study at the gymnasium. The teaching staff includes 77 teachers (most of the teaching staff have the highest qualification category), 8 teachers of additional education and 7 administration staff. The gymnasium provides in-depth training in humanitarian subjects. It is compulsory to study two foreign languages: English and French. The gymnasium is distinguished by its rather good technological infrastructure. From the tenth grade, students can choose one of the three education profiles: humanitarian, technological and universal.

In accordance with the Federal State Educational Standard, each teacher independently determines the educational and methodological complex in the subject taught. According to the selected teaching materials, the members of the departments (there are seven 
educational departments in the gymnasium) draw up a curriculum. The academic year lasts at least 34 weeks, except for first-grade schoolchildren (33 academic weeks). The maximum load for a 6-day school week is 35-36 hours. Classes start at 8:00, training is carried out in two shifts. The number and sequence of lessons is determined by the curriculum and timetable.

The educational process is based on the following principles: classroom-lesson system; advisory support; project and research activities; elective special courses for students in 9-11 grades.

Thus, Gymnasium no. 5 is a typical gymnasium, it does not fundamentally differ from other gymnasiums. Students can also be called typical representatives of schoolchildren studying in other secondary schools. This conclusion is supported by the results of in-depth interviews with individual teachers from the gymnasium. There was also taken into account the general picture of the consequences brought about by the transition to "distance" learning and teaching during the pandemic on the part of the teaching staff. This supplemented the results of the narrative analysis of the seventh-grade students' essays.

The task to write a discursive essay was given to all seventh-grade students at the end of the last academic quarter of 2020 at the end of the distance learning period. This work had to be completed and submitted in the period from May 25 to May 29, inclusive. Most of the students coped with the assignment and completed the work on time. On average, checking and processing one essay took about fifteen minutes.

\section{RESULTS AND DISCUSSION}

A total of 54 works were processed. It was interesting to study the experience of each student, to generalize and come up with ideas of what can be improved and adjusted in distance learning format.

It was rather simple to interpret the students' formulations, because in fact every work was structured in such a way that students tried to highlight the "pros" and "cons" of this new education form. Here are some examples of adolescents' answers: “....as a great disadvantage of this form of education, I consider the absence of real contact between the student and the teacher". It should be noted that this fact, formulated in one way or another, was pointed out in every work. All teenagers emphasized the need for "live" communication, both with the teacher and with classmates: "It was not easy for me to study new material on my own", or "if earlier you could ask the teacher questions immediately after the lesson, find out what remained incomprehensible, now there was no such opportunity". The seventh-grade students often concluded their essays in the following way: "Traditional education is more effective than distance learning" or "I would prefer to go to school and obtain knowledge in the classroom".

There were also positive trajectories of narratives, for example: "An unambiguous plus of this situation is a huge amount of time spent with my family", "Distance learning for me personally made it possible to devote more time to my favourite activities - drawing, knitting, embroidery".

Speaking about the advantages of distance learning, indicated by the gymnasium students, one cannot fail to note the following original and, to a greater extent, unexpected wording: "It is obvious that distance education will lead to a decrease in education costs in general, interactive whiteboards, and also, the cost of heat, electricity and water supply will decrease". The students suggested that the money saved could be spent on increasing teachers" salaries. Continuing the discussion about saving money, the students noted the following advantage: "the daily spending of money on travel and food decreased".

In general, the students' thoughts and reasoning turned out to be curious and varied. In most essays young teenagers stressed the "pros" and "cons" of distance learning, giving weighty arguments to support their views. At the same time, in most of the essays, students stated that "distance learning has much fewer advantages than disadvantages". At the same time, in $6.6 \%$ of essays, the students did not point out a single "minus", arguing that "It's much more comfortable to study at home than at school," and "It did not influence my working capacity," and some students claimed that they were even able to improve not only their grades, but also knowledge in a particular subject.

Analysis and clustering of narratives made it possible to structure and isolate both individual and collective trajectories in the judgments of seventh-grade students, to compile their rating in terms of frequency (intensity) of mention.

Positive trajectories: the ability to study at home, being in familiar and comfortable environment (mentioned in $94.4 \%$ essays of the total number); no need to get up early to get to school on time (74.1\%); the possibility to study from any place, the only necessary condition being access to Internet $(68.5 \%)$; the ability to independently plan the daily routine $(64.8 \%)$; the opportunity to be more often with the family (many students pointed out a lack of communication with parents due to their work responsibilities; 48.1\%); The opportunity to devote more time to favourite activities, hobbies (27.8\%); saving money on travel, food and other costs associated with daily school attendance (14.8\%); reducing the costs of providing the educational process in schools (1.9\%).

Negative trajectories: lack of "live" contact with the teacher and classmates $(100.0 \%)$; the need to spend a lot 
of time at the computer, which can affect health, for example, visual deterioration (92.6\%); the inability to control the independence of completing tasks - the quality of the acquired knowledge suffers (87.0\%); troubles with the Internet connection, online platforms on which distance learning is delivered (74.1\%); lack of the necessary control on the part of the teacher - there is no one to ask questions that arise in the course of work $(64.8 \%)$; lack of the usual daily routine, study discipline, which is requested during the classroom learning at school $(55.6 \%)$; there is no opportunity to come to the consultation to ask the teacher questions $(51.9 \%)$; self-organization problem $(46.3 \%)$; lack of high-quality, high-speed Internet at the student's location (house, summer cottage in the village; 40.7\%); insufficient availability of gadgets (in the family there are two and three children studying remotely; $31.5 \%$ ); insufficient computer literacy (both on the part of students and on the part of teachers; $18.5 \%$ ); lack of practical, laboratory and experimental work (18.5); lack of physical activity, physical education lessons in the standard format $(11.1 \%)$.

In general, more negative trajectories were recorded than positive ones: 13 and 8 , respectively. The calculated index of distance learning positive qualities to its negative characteristics was 0.615 (calculated according to the Equation (1): 8/13).

The average intensity of qualitative negative characteristics was $79.6 \%$; positive - $52.8 \%$. The calculated ratio index of the intensity of the distance learning positive qualities to the negative ones was 0.663 (calculated by the Equation (1), 52.8 / 79.6).

The difference in the intensity (frequency) of mention of distance learning positive and negative qualities is clearly shown in Figure 1.

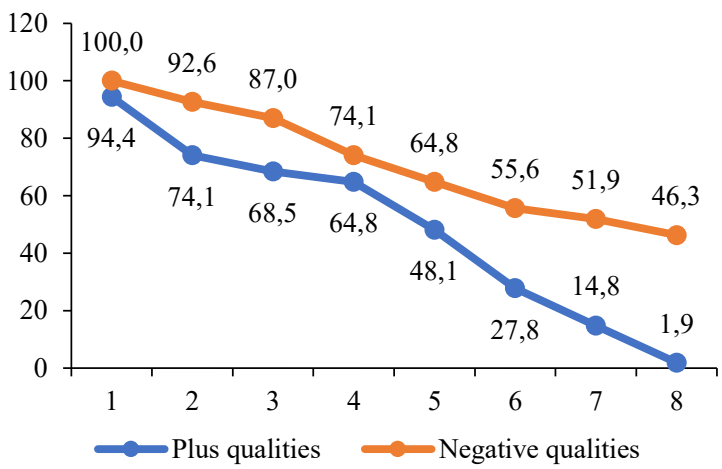

Figure 1 The ratio of the intensity (frequency) of mention of positive and negative qualitative characteristics of distance education.

According to the proposed method for determining the sustainability of the distance education format, the sustainability index is:

$$
I=\sqrt[2]{0.615 \times 0.663}=0.639
$$

Thus, in the modern infrastructural and methodological conditions, the distance learning format does not allow to ensure the sustainable quality of adolescents' human capital formation.

In addition to the above-mentioned positive and negative narrative trajectories, a third cluster was identified, when the same argument was attributed by the students to both "positive" and "negative qualities". For example: lack of regime, discipline - 6 students (11.1\%); inability to control the independence of completing tasks - 5 students $(9.3 \%)$; lack of physical education lessons - 2 students $(3.7 \%)$.

The results obtained indicate that, in general, thirteen-year-old adolescents have more or less adapted to distance learning, even managed to identify its advantages. It should be noted that this result was obtained due to the work of the administrative and pedagogical staff. Based on the results of the in-depth interviews with individual teachers, the atmosphere in the team during the pandemic can be assessed as predominantly favorable. At the very beginning of the transition to distance learning, there was observed some excitement, even rejection among schoolteachers, especially older teachers. This group of teachers was not always successful in coping with the technical challenges of teaching at a distance. Younger teachers dealt without much difficulty both with online educational platforms and with various webinar systems.

The key challenge the teachers faced was that they had to tune not only themselves to the new format of education, but also their students. Why was it difficult? Many students perceived the beginning of the quarantine and, in this regard, the distance learning format as another vacation. Some students failed to connect to video lessons (giving inadequate excuses such as oversleeping, poor memory, etc.), in which, as a rule, teachers explained a new topic or material that is hard to study independently. Naturally, such a student subsequently could not cope with the control task, because he did not know the material, did not receive enough knowledge on the topic. Frequently, this situation resulted in conflicts, involving - a teacher, a student, and a parent (or parents).

The teachers had to revise their teaching program and determine which topics were for compulsory study, despite the unusual teaching and learning format, and which could be transferred to the next academic year. There was a great need to adjust the calendar-thematic planning, taking into account the use of distance learning technologies.

One more disadvantage of distance learning for teachers is the need to constantly be in touch with 
students and parents through various messengers. Parents asked for feedback, and that was a standard practice, it was to be organized. But unfortunately, many parents and students did not comply with the established time frames for communication, demanding an answer to their question "here and now".

It is important to note that the school administration provided all possible support to teachers and parents. Various courses were arranged to assist teachers and students in mastering the online educational platforms. The school psychologist provided the necessary recommendations for organizing the educational process at a distance, conducted webinars, and talks both with teachers and parents.

\section{CONCLUSION}

A narrative analysis of the discursive essays written by seventh grade adolescents showed that gymnasium students pointed out more negative rather that positive aspects of the distance education.

In their essays, students state that distance learning is acceptable, but as a temporary measure due to an urgent need: a local epidemic, a pandemic, or the inability to attend school for an adequate excuse. This form of education, according to most students, clearly has its "pluses", but they are outweighed by "minuses". Some students mention that a partial transition to this form of education could be convenient, especially when it comes to additional education. Gymnasium students would still prefer to receive education in the standard form - at traditional classroom lessons with a teacher and classmates. From the teaching staff viewpoint, faceto-face lessons at school are also more familiar and more convenient than lessons at a distance. However, the experience gained during this period of study is useful and unambiguously necessary, both for students and teaching staff, as well as parents.

The introduction of distance learning technologies into the secondary education system on an ongoing basis in modern conditions will lead to a decrease in the effectiveness of the process of accumulating human capital by adolescents. Nevertheless, upon careful consideration of the negative narrative trajectories in the judgments of the gymnasium students, one can see that some of the disadvantages can be removed by improving technological infrastructure, increasing digital literacy, adapting the calendar-thematic plan with the allocation of compulsory hours of online consultations. Parents can help to offset the other part by organizing live communication between adolescents and peers in hobby groups. For adolescents living in remote settlements, where there are no schools or they are not staffed with subject teachers, distance education can ensure providing a high-quality basic human capital given the school itself is subject to significant transformations, as well as its resource base, calendarthematic planning, and teaching methods.

Practical evaluation of the methodological approach to assessing the sustainability of distance education by the parameter "quality" has shown its viability. The transition to distance education without compromising the quality of adolescents' human capital formation will be possible if, according to the results of measuring the sustainability index, the indicator is at least 0.95 on average for the entire group of typical educational institutions operating in the territory of both central and remote settlements. Currently, we can conclude that the complete transition to distance education is premature.

\section{REFERENCES}

[1] T. Markova, Educators' and students' perceptions of online distance education before and amid COVID-19: key concerns and challenges. SHS Web of Conferences, 99 (2021) pp. 1-6. DOI: https://doi.org/10.1051/shsconf/20219901018

[2] C.A. Ionescu, L. Paschia, N.L. Gudanescu Nicolau, S.G. Stanescu, V.M. Neacsu Stancescu, M.D. Coman, M.C. Uzlau, Sustainability analysis of the e-learning education system during pandemic period-covid-19 in Romania. Sustainability, 12(21) (2020) pp. 1-22. DOI: https://doi.org/10.3390/su12219030

[3] A.Sharpe, The development of indicators for human capital sustainability, Montreal, McGill University, 2001.

[4] I. Šlaus, G. Jacobs, Human capital and sustainability. Sustainability, 3(1) (2011) pp. 97154.

[5] A.N. Perret-Clermont, C. Pontecorvo, L.B. Resnick, T. Zittoun, B. Burge (Eds.), Joining society: Social interaction and learning in adolescence and youth, Cambridge, Cambridge University Press, 2004.

[6] R. Antonini Philippe, A. Schiavio, M. Biasutti, Adaptation and destabilization of interpersonal relationships in sport and music during the Covid19 lockdown. Heliyon, 4 (2020) pp. 1-6. DOI: https://doi.org/10.1016/j.heliyon.2020.e05212

[7] United Nations Development Programme, Sustainable Development Goals, 2015. Available online:

http://www.undp.org/content/undp/en/home/sustain able-development-goals.html

[8] Education for sustainable development goals: learning objectives, Paris, UNESCO, 2017. 
[9] T. Zhang, Z.A. Shaikh, A.V. Yumashev, M. Chła $c_{c}$, Applied model of e-learning in the framework of education for sustainable development. Sustainability, 12 (2020) pp. 1-15. DOI: https://doi.org/10.3390/su1216642010

[10] I. Lampă, A. Greculescu, L.L. Todorescu, Education for sustainable development-Training the young generation for the Future. ProcediaSocial and Behavioral Sciences, 78 (2013) pp. 120-124. DOI: https://doi.org/10.1016/j.sbspro.2013.04.263

[11] R. McKeown, V. Nolet, Education for sustainable development in Canada and the United States, in: Schooling for sustainable development in Canada and the United States, Springer, Dordrecht, 2013. pp. 3-21.

[12] R. Laurie, Y. Nonoyama-Tarumi, R. Mckeown, C. Hopkins, Contributions of education for sustainable development (ESD) to quality education: A synthesis of research. Journal of Education for Sustainable development, 10(2) (2016) pp. 226-242. DOI: https://doi.org/10.1177\%2F0973408216661442

[13] D. Adams, Defining educational quality, Arlington, Institute for International Research, 1993.

[14] M. Hannay, T. Newvine, Perceptions of distance learning: a comparison of online and traditional learning. Journal of online learning and teaching, 2(1) (2006) pp. 1-11.

[15] T. Markova, I. Glazkova, E. Zaborova, Quality issues of online distance learning, in: ProcediaSocial and Behavioral Sciences, 237 (2017) pp. 685-691.

DOI:

http://dx.doi.org/10.1016/j.sbspro.2017.02.043 